\title{
Developing a neonatal workforce: role evolution and retention of advanced neonatal nurse practitioners
}

\author{
S L Smith, M A Hall
}

Arch Dis Child Fetal Neonatal Ed 2003;88:F426-F429

See end of article for authors' affiliations

......................

Correspondence to: Dr Hall, Department of Neonatal Medicine, Princess Anne Hospital, Coxford Road,

Southampton, Hampshire SO16 5YA, UK;

mh10@doctors.net.uk

Accepted

22 October 2002
20 advanced neonatal nurse practitioners (ANNPs) Background: Over the past decade more than 120 advanced neon
have graduated from the Southampton based ANNP programme.

have graduated from the Southampton based ANNP programme.
Objectives: To determine the scope of practice and evolving role of ANNPs and to identify factors that may affect future recruitment and retention.

Method: An open ended structured questionnaire on clinical role, working arrangements, retention and attrition, continuing education, and professional development was sent to 95 ANNPs.

Results: A response rate of $83 \%$ was achieved. There was an attrition rate of $14 \%$, with most ANNPs remaining in their original seconding unit. Factors considered to be important for role satisfaction included a well defined role, working within a team of ANNPs, appropriate remuneration, and evidence of unit support for both role definition and continuing professional development.

Conclusions: Although ANNPs are expensive to both train and employ, this evidence suggests that there is a good return on the investment in terms of retention to the unit and the specialty. Their role incorporates many features of advanced nursing practice as well as providing "value added" neonatal care by merging traditional medical and nursing roles and crossing professional boundaries. In 2004 the manpower challenges for neonatal units will be even more acute; these data confirm that there are effective options available but they require long term strategic planning and investment.

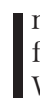
$\mathrm{n}$ the late 1980s in the former Wessex Region, an interprofessional group recruited from the 10 neonatal units in Wessex was established to evaluate the standards and quality of neonatal care provision. At the time, there was a perceived need to improve the consistency of care delivered in units of all sizes as well as to re-evaluate a possible mismatch of education, skills, and training in the provision of care. Experienced neonatal nurses expressed a desire to develop their roles if education and training were provided and appropriate remuneration agreed. These nurses were not prepared to consider purely extending their role but wanted the opportunity to develop both professionally and personally while still providing direct clinical care for neonates and their families. ${ }^{1}$ Fortuitously, at the same time, a number of related changes were also taking place; the Patients' charter was introduced, ${ }^{2}$ which explored new ways of working, and the United Kingdom Central Council published the Scope of professional practice, which encouraged the nursing profession to "look beyond the traditional boundaries which had hitherto restricted practice". ${ }^{3}$

In 1992, the first advanced neonatal nurse practitioner (ANNP) training course was introduced in Southampton, and the subsequent introduction of qualified ANNPs into units in the United Kingdom was an acknowledgement that there were alternatives to the traditional roles of delivery of acute neonatal care, provided that the importance of appropriate educational underpinning was acknowledged. ${ }^{4}$ Since 1992 there have been a number of reports about changes in professional boundaries resulting from drivers including the reduction in the hours worked by junior doctors required by the "New Deal" : the limitations on the duration of training imposed by The Calman report, ${ }^{6}$ the empowerment of nurses to take on new roles as suggested in the UKCC Scope of professional practice, $^{3}$ and the recent requirements of clinical governance. ${ }^{7}$ The resulting change in professional boundaries has produced "a complex picture of perceived benefits and problems for patients, junior doctors and nurses", and the requirements for appropriate educational underpinning and professional recognition have been emphasised. ${ }^{8}$
Despite the enthusiasm of many, concerns have been expressed about a number of aspects of the ANNP role: apart from issues of clinical competence, there have been doubts about both the long term viability of a role based perpetually in the acute clinical setting and the long term career options for such nurses. ${ }^{9}$ These concerns have led some to question whether the relatively expensive investment in the education and training of these new professionals would be justified.

The Southampton course has now been in progress for over a decade, and more than 120 practitioners have qualified, seconded by about $28 \%$ of district general hospitals and $45 \%$ of tertiary neonatal units in the United Kingdom. Currently, NHS neonatal workforce confederations are considering strategies to address the long term workforce challenges for all specialties, and the recruitment of ANNPs may be a viable option to be considered for neonatology. The purpose of this paper is to present the findings of a study on the evolving role of ANNPs and factors affecting their recruitment, retention, and integration into the neonatal workforce on a local, regional, and national level.

\section{METHODS}

In February 2002, a qualitative study was conducted using a semistructured open ended questionnaire with the aim of exploring and identifying the current scope of practice, level of attrition and retention, aspirations for professional development, and continuing education of ANNPs. The questionnaires were posted to all graduates with an accompanying letter which outlined the purpose of collecting the data. Responses were anonymous, and all the data were collated (by one of the ANNP course coordinators (SS)).

\section{Sample}

At the time of the study, 109 ANNP graduates had qualified from the Southampton course. Questionnaires were sent to 95 of them $(86 \%)$. The remaining 14 were not contacted for the following reasons: we had no current address for six; contact 
Table 1 Characteristics of Southampton qualified advanced neonatal nurse practitioners (ANNPs) who responded to the questionnaire $(n=79)$

\begin{tabular}{ll}
\hline Median age (range) & 42 years (28-52) \\
\hline M/F & $4 / 75$ \\
Marital status & $45(57 \%)$ \\
$\quad$ Married & $29(37 \%)$ \\
Single & $5(6 \%)$ \\
$\quad$ Divorced & $68(86 \%)$ \\
Working as ANNP & $59(87 \%)$ \\
Of those working as ANNPs (68) number in & \\
original seconding unit & \\
Type of neonatal unit & $28(41 \%)$ \\
$\quad$ District general hospital & $40(59 \%)$ \\
$\quad$ Tertiary &
\end{tabular}

was considered inappropriate because of personal circumstances for four; four were working outside of Europe (as ANNPs). Seventy nine replies (83\%) were received.

\section{RESULTS}

Table 1 outlines the characteristics of the study population.

\section{Mobility of practising ANNPs}

Of the 68 nurses still working as ANNPs, nine have left their original seconding unit. In a small number of cases (three), the reason for the move was related to family commitments, but the remaining ANNPs left because they perceived a lack of commitment on the part of the neonatal unit to develop and support the role.

Of the 59 ANNPs who are still working in their original unit, more than half $(58 \%)$ would consider moving away. Factors that would encourage this move include:

- a more defined role with increased autonomy and "hands on experience";

- the composition and structure of the interprofessional neonatal team;

- not working on the senior house officer rota;

- an increase in salary.

\section{Attrition}

Of the 79 respondents, 11 are currently not practising as ANNPs, and of these only one would consider assuming the role in the future. Four of these ANNPs had problems with shift patterns, child care, and a lack of flexibility between the two, two were offered senior management posts, one moved house, one reported a lack of support and guidance, one did not enjoy the role, one felt there was little scope for further development, and one did not wish to give a reason for leaving.

\section{Clinical role and funding of ANNPs in district general hospitals and regional neonatal units}

There is little doubt that there are many interpretations of the ANNP role, and to some extent this seems to be dependent on the needs of the unit, the multiprofessional team, and the individual. However, when reviewing and comparing the primary components of the role within district general hospitals and regional neonatal units, there is no significant difference in the daily clinical functioning and the scope of practice of ANNPs. Most are undertaking a senior clinical role incorporating both the medical and nursing management of neonates and their families. Individual clinical practice ranges from managing a caseload on the postnatal ward to functioning clinically at a level equivalent to that of both senior house officer and "middle-grade" medical staff or that of a consultant neonatal nurse. It seems that, irrespective of the diversity of clinical practice, the fundamental principles of "advanced practice" as defined by Davies and Hughes ${ }^{10}$ are in evidence. Almost all ANNPs (98\%) are actively and regularly involved in education both within the clinical environment and in the classroom where they teach nurses, junior doctors, parents, midwives, and students undertaking specialised neonatal courses including student ANNPs. Topics covered range from resuscitation and how to undertake clinical procedures to the use of equipment and neonatal nursing theory and practice. In the clinical area, almost all ANNPs report to middle grade medical staff or consultants, but within an established ANNP team the more junior ones will report in the first instance to a more senior ANNP.

One of the major limitations and frustrations of practice highlighted in the survey is that of "prescribing". Half of the ANNPs are "ordering" medications, and the majority are doing so within patient group directions; however, this continues to be a major issue and challenge for ANNPs both in the neonatal unit and on the postnatal ward.

Table 2 gives a comparison of the clinical functioning of ANNPs working in different types of unit.

\section{Funding}

There seems to be no difference in the salaries paid to ANNPs in either type of neonatal unit. Currently $72 \%$ of all practising ANNPs are paid at $\mathrm{H}$ grade or equivalent, $18 \%$ at $\mathrm{G}$, and the remainder at I grade or equivalent, with more than $80 \%$ receiving extra duty payments for "out of hours" work. Although it is often perceived that ANNPs are replacing junior doctor hours, less than 12\% of ANNPs are fully funded from a medical budget, the rest being primarily funded from either the nursing budget or a completely separate budget. The $25 \%$ of the ANNPs funded from a separate ANNP budget have an independent shift rota in which the most common working arrangement is a division of time between medical and nursing rotas.

\section{Career progression and continuing education}

ANNPs were asked whether they perceived themselves to be in a "career cul-de-sac". Their views were divided: $28 \%$ felt the statement did not apply to them, 35\% agreed with the statement, and 37\% were unsure. The main theme that emerged was that, although the statement may be accurate for some ANNPs, there were many ways for practice to diversify and it is the responsibility of the individual to ensure that their scope of practice develops. A more important cause for concern relates to the feeling of some ANNPs that there is no formalised support for a defined career structure, little recognition of their value as team members, and no professional recognition of the role from the nursing regulatory bodies.

With regard to continuing education and personal development, most ANNPs $(>80 \%)$ do have access to funding for continuing education study days. However, concerns have been raised about the relative paucity of study days that are at the correct level and have the appropriate content. It would seem to be very important that any provision of continuing education should be responsive to the needs of the ANNPs. Some have already decided to undertake an MSc in nursing, but, if there was the opportunity to undertake an MSc specific to neonatal care, more than $85 \%$ stated that they would wish to access such a course and about $90 \%$ would choose to do that as open and distance learning. As far as clinical competency and levels of advanced practice are concerned, more than 75\% stated that they would consider undertaking the higher level assessment process, ${ }^{11}$ although at the present time this is not possible until the Nursing and Midwifery Council (NMC) defines the future regulation of post-registration practice.

\section{DISCUSSION}

In the decade since the initiation of the Southampton ANNP course, there have been many debates about the clinical role of 
Table 2 Comparison of the clinical functioning of advanced neonatal nurse practitioners (ANNPs) working in district general hospitals (DGHs) and regional neonatal units

\begin{tabular}{llllll}
\hline $\begin{array}{l}\text { Type of } \\
\text { unit/number of } \\
\text { ANNPs }\end{array}$ & $\begin{array}{l}\text { Grade/ } \\
\text { equivalent } \\
\text { salary scale }\end{array}$ & $\begin{array}{l}\text { Orders } \\
\text { medication }\end{array}$ & $\begin{array}{l}\text { Involved in } \\
\text { audit }\end{array}$ & $\begin{array}{l}\text { Participates in } \\
\text { clinical } \\
\text { governance }\end{array}$ & $\begin{array}{l}\text { Role involves } \\
\text { education }\end{array}$ \\
\hline Regional/40 & $\begin{array}{l}1 / 12 \% \\
\mathrm{H} / 73 \%\end{array}$ & $18(45 \%)$ & $34(85 \%)$ & $21(53 \%)$ & $39(98 \%)$ \\
& $\mathrm{G} / 15 \%$ & & & & \\
& $1 / 7 \%$ & $16(57 \%)$ & $25(89 \%)$ & $19(68 \%)$ & $28(100 \%)$ \\
DGH/28 & & & & \\
& $\mathrm{G} / 71 \%$ & & & & \\
\hline
\end{tabular}

ANNPs and their cost effectiveness. However, it appears that demand for such a professional continues, as there are currently a number of vacant posts throughout the United Kingdom, and 2002 has seen the highest number of applicants ever (25) for entry to the Southampton course. To date, however, in the United Kingdom there have been no studies that have focused attention on recruitment, role satisfaction, employment conditions, professional development, attrition, and retention. There is little doubt that considerable investment is required when seconding a neonatal nurse to an accredited ANNP course in terms of finance, unit manpower, personal commitment, and support. The responsibilities for success are shared by the student, the neonatal unit, the employing trust, and the education providers. It is imperative therefore that the initial investment is seen to benefit all stakeholders in terms of both quality of care provision and retention to the unit and also to the specialty. Despite the initial reservations about the introduction of ANNPs, ${ }^{12}$ more than 200 are currently practising in a variety of settings in the United Kingdom. Recent evaluation studies suggest that not only have they been accepted within neonatal units but also their knowledge and experience is valued both within the specialty and to a greater extent within the context of specialist health care. ${ }^{13}$

Evaluation data on clinical effectiveness are to date scanty, but two recent studies have highlighted the fact that ANNPs are able to provide care that is at least equal, if not in some cases superior to, that being provided by medical staff. ${ }^{14}{ }^{15}$ Other reports suggest that the investment made by neonatal units throughout the United Kingdom into the development of ANNPs has been worth while in terms of workforce planning and overall improvements in education and care provision. ${ }^{16}$

The Southampton graduates have for the most part remained in their original seconding units, and they have been able to provide a standard of care that is consistent, reliable, and safe, and which incorporates many of the characteristics of advanced nursing practice. The ANNP workforce primarily comprises women with families, and our data confirm that some have had to leave their posts because of problems with child care arrangements. In many cases, ANNPs are working shift patterns that are not conducive to family life in both the short and long term, and it may be that, to improve retention, a more flexible approach to working arrangements will have to be considered.

The components of this role are multifaceted, yet few could dispute that ANNPs are in a unique position to have a direct and positive impact, not only on patient and family care but also on interprofessional working and collaboration within neonatal units. As models of neonatal care delivery are restructured, new ways of working will need to be accepted, and there is likely to be even more blurring of professional boundaries. The role of the ANNP provides an example of a model of care that has cut across these boundaries, and, in doing so, it can offer the opportunity to provide patient centred high quality neonatal care. For the innovation to succeed and develop, managers will need to be fully aware of the long term issues that need to be addressed on a local, regional, and national level; these include foresight and planning on role definition and integration, professional and personal development opportunities, continuous appraisal of the needs of the service, the unit, and the individual, and appropriate remuneration.

Recently the BMA's Health Policy and Economic Research Unit (HPERU) has presented a discussion paper outlining a future model for the healthcare workforce. The two main aims are to make the best of the skills of the healthcare team and to respond to the needs of patients. ${ }^{17}$ It is suggested that improvements in efficiency would be brought about by "making the best use of doctors' clinical skills"-nurses would coordinate the care around a patient while doctors, who are a more expensive resource, should concentrate on the areas where their skills can be used. Although there are few who would dispute the aims of the HPERU, the experience from the ANNP initiative would suggest that, to provide the best quality of care, the skills of all professionals must be developed to their full potential.

Currently, for ANNPs, a major limiting factor to effective clinical practice is prescribing, and this is in turn having an impact on the provision of neonatal care and the workload of medical colleagues. This issue has been debated and discussed since the early 1990s, and, although currently 50\% of ANNPs are "ordering" medication using patient group directions, there remains a lack of clarity and consistency between Trusts, particularly in relation to the use of unlicensed drugs. The NMC has recently issued the following advice for "potential" nurse prescribers ${ }^{18}:$ "If a medicine is unlicensed, it should only be administered to a patient against a patient-specific prescription and not against a patient group direction". The dilemma and debate about whether ANNPs should be undertaking this practice will continue until the situation is clarified. The recommendations from the "Proposals for supplementary prescribing" document are due to be published later this year, ${ }^{19}$ and it is hoped that a positive response will be forthcoming which will enable ANNPs to "order" unlicensed drugs provided that they have completed the appropriate accredited educational prescribing course. This may be the first step forward in enabling appropriately educated ANNPs to maximise fully their potential by providing continuity of care without the current limitations and frustrations.

Evidence to date, including the results of this survey, indicates that the development of ANNPs has provided a relatively stable addition to the workforce in this specialty despite uncertain career opportunities and a degree of opposition from both medical and nursing colleagues. However, these are data from only one university training course for ANNPs whose specific learning outcomes are not directly transferable to other similar courses in the United Kingdom. To gain a 
Summary points

- ANNPs have now been in post in the United Kingdom for more than 10 years, and the numbers are steadily increasing.

- ANNPs now form an important component of the workforce in many neonatal units.

- ANNPs provide an effective alternative to the current models of care providers.

- For ANNPs prescribing is currently a major limitation to providing continuity of neonatal care.

- To date, ANNP "graduates" have tended to remain in their original seconding unit.

- The return on investment for neonatal units is good, with a retention rate over a $5-10$ year period of $70-80 \%$

- Attrition is low and is associated with a lack of commitment and support to the evolving professional role.

- The future professional development and the retention of ANNPs in clinical practice demands careful planning and investment

broader perspective of how other ANNPs are functioning and the ways they have contributed to neonatal care would require further data collection and evaluation from other courses that offer similar training for ANNPs. It is likely that this will take some time as there are only a few courses in the United Kingdom and generally the number of ANNPs in training is small.

The introduction of ANNPs seems to have enabled the primary aim of maintenance and possible improvement in quality of neonatal care provision to be realised; to promote the future growth and development of ANNPs the next step is to address the challenges of providing more secure professional integration and career development.

\section{Authors' affiliations}

S L Smith, Division of Child Health, School of Nursing and Midwifery, University of Southampton, Southampton, UK

M A Hall Department of Neonatal Medicine, Southampton University

Hospitals NHS Trust, Southampton

\section{REFERENCES}

1 Hall MA, Smith SL, Jackson JE, et al. Neonatal nurse practitioners: a view from Perfidious Albion? Arch Dis Child 1992;67:458-62.
2 Secretary of State for Health. The NHS plan. London: Stationery Office, 2000.

3 United Kingdom Central Council for Nursing, Midwifery and Health Visiting. The scope of professional practice. London: UKCC, 1992.

4 Redshaw M, Harris A. Breaking new ground: an exploratory study of the role of the advanced neonatal nurse practitioner and the educational programme of preparation. London: English National Board for Nursing, Midwifery and Health Visiting, 1995:15.

5 NHS Management Executive. Junior doctors. The new deal. London: NHSME, 1991.

6 Department of Health. Hospital doctors: training for the future. Report on the Working Group on Specialist Medical Training (the Calman Report). London: DOH, 1993.

7 Department of Health. A health service of all the talents: developing the NHS workforce: consultation documents on the review of workforce planning. London: Stationery Office April, 2000. http:// www.doh.gov.uk/pdfs/workforce.pdf (accessed 21 May 2002).

8 Dowling S, Barrett S, West R. With nurse practitioners, who needs house officers? BM 1995;311:309-13.

9 DiCenso A. The neonatal nurse practitioner. Curr Opin Pediatr 1998; 10:151-5.

10 Davies B, Hughes AM. Clarification of advanced nursing practice: characteristics and competencies. Clin Nurse Spec 1995;9:156-60.

11 Report of the higher level of practice: pilot and project http://www.nmc-uk.org/cms/content/Publications/ HLP\%2OREPORT.pdf (accessed 10 May 2002).

12 Doherty LE. The advanced neonatal nurse practitioner: room for one more? Journal of Neonatal Nursing 1996;2:23-5

13 Britton JR. Neonatal nurse practitioner and physician use on a newborn resuscitation team in a community hospital. J Pediatr Health Care 1997; 11:61-5.

14 Aubrey WR, Yoxall CW. Evaluation of the role of the neonatal nurse practitioner in resuscitation of preterm infants at birth. Arch Dis Child Fetal Neonatal Ed 2001;85:F96-9.

15 Lee TWR, Skelton RS, Skene C. Routine neonatal examination: effectiveness of trainee paediatrician compared with advanced neonatal nurse practitioner. Arch Dis Child Fetal Neonatal Ed 2001;85:F100-4.

16 Hall D. Wilkinson A. Neonatal services provided by Advanced Neonatal Nurse Practitioners at Ashington: what have we learned in the last five years? http://www.rcpch.ac.uk/publications/ recent_publications/Ashington_Report.pdf (accessed 1 May 2002).

17 BMA Health Policy and Economic Research Unit. The future healthcare workforce: a new model for NHS care. Discussion paper 9 February 2002. http://www.bma.org.uk (accessed 22 May 2002).

18 Nursing and Midwifery Council. Advice on the administration of medicines: legislation. http://www.nmc-uk.org/cms/content/Advice/ Legislation\%20relating\%20to\%20administration\%20of\%20medici nes.asp (accessed 15 September 2002).

19 Department of Health. Proposals for supplementary prescribing by nurses and pharmacists and proposed amendments to the prescription only medicines (Human Use Order 1997) London: Stationery Office, 2002 http://www.doh.gov.uk/supplementaryprescribing/ laccessed 15 September 2002) 